\title{
KESEIMBANGAN ANTARA AKSI-REAKSI GAYA LUAR BANGUNAN SEBAGAI KERAMAHAN TERHADAP ALAM SEMESTA: Diskursus
}

\author{
Rita Laksmitasari Rahayu \\ Arsitektur, Universitas Indraprasta PGRI \\ ritalaxmi@gmail.com
}

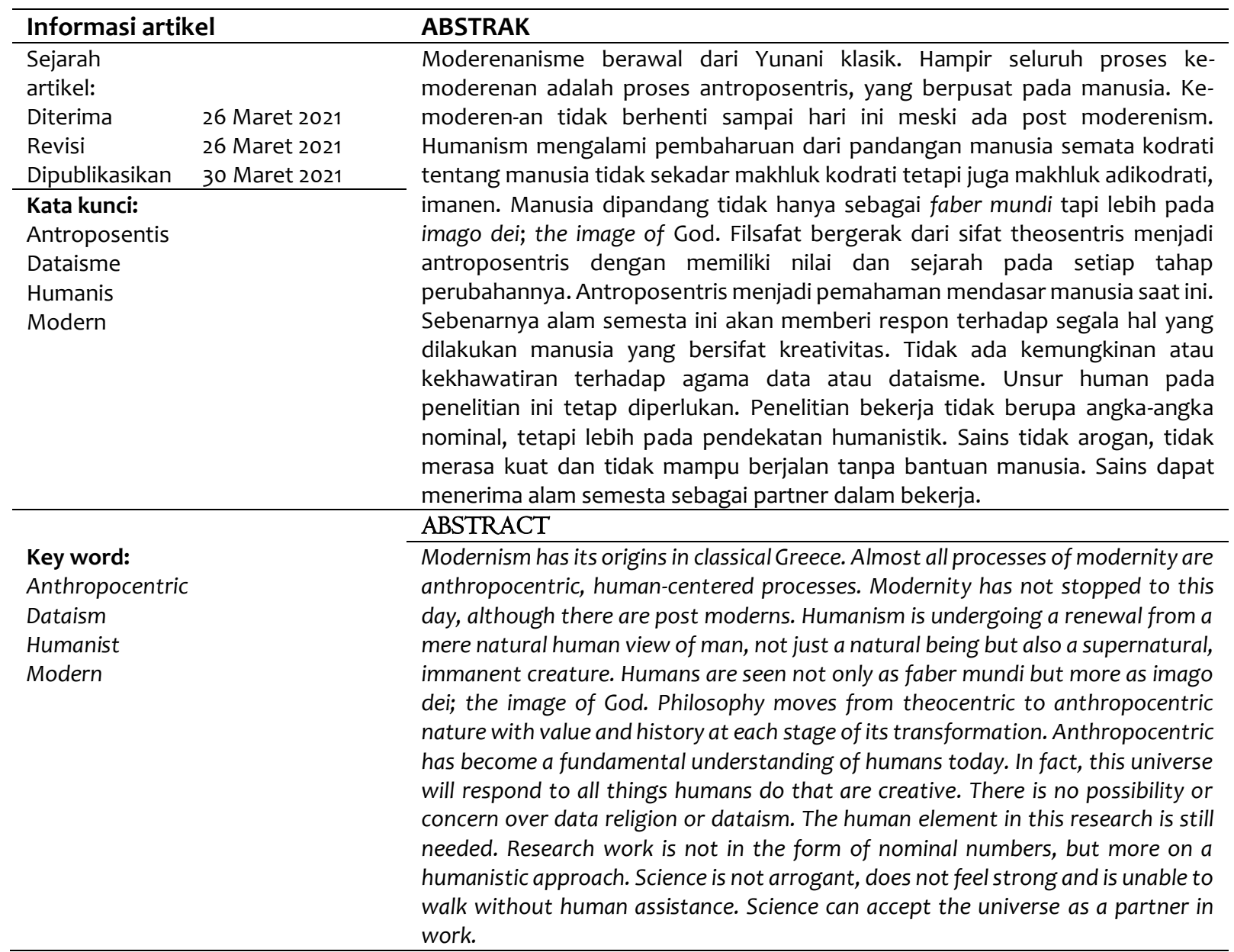

\section{PENDAHULUAN}

Moderenanisme berawal dari Yunani klasik. Hampir seluruh proses ke-moderenan adalah proses antroposentris, yang berpusat pada manusia. Aneka pemikiran ke-moderen-an dapat dikatakan aneka bentuk humanisme. Pembentuk modernitas juga dapat dikatakan bentuk humanisme yaitu: humanisme, protestantisme, rasionalisme, romantisisme, kapitalisme. Bentuk ke-moderen-an memiliki banyak wajah, artinya dapat dikritik dari berbagai sisi. Moderenitas sesuatu yang sangat kompleks dan ada kaitannya dengan post moderenisme. Ke-moderen-an tidak berhenti sampai hari ini meski ada post moderenism. Humanisme suatu gerakan kultural, tidak eksklusif di wilayah filsafat, meskipun merumuskan diri dalam perjalanan filosofis dan hampir semua aliran filsafat di kemudian hari memang bentuk dari variasi dari humanisme. Tapi awalnya adalah gerakan kultural yang dimulai pada abad ke 14-16.

Masa Renaisans, masa kelahiran kembali semangat budaya Yunani klasik. Semangat Yunani klasik semangat kebebasan berpikir, penghargaan terhadap tubuh, tendensi demokrasi, tapi juga keleluasaan ekspresi artistik. Waktu zaman kekuasaan Gereja semakin mutlak dan korupsinya semakin 
mutlak juga. Berpikir mulai sangat kritis dan mencoba melepaskan diri dari kungkungan gereja, maka muncul reaksi masa Renaisans yang dipelopori oleh kaum kaum awam. Pengetahuan hampir dan seluruh kecanggihan kultural dikuasai kalangan yang mendapat pendidikan, terutama para pastor, bruder dan bangsawan. Diluar kalangan tersebut itu tidak pernah mendapatkan pendidikan yang cukup serius. Pada zaman itu, sekolah-sekolah menjadi satu dengan biara atau katedral atau gereja gereja besar. Bersamaan dengan kondisi tersebut, mulai muncul orang-orang awam yang belajar sendiri, dan memiliki prinsip adalah pertama tama bukan Tuhan tapi manusia segala galanya. Gerakan ini terjadi karena sudah terlalu lama mereka hidup dalam suasana gereja yang sedikit-sedikit dikaitkan dengan dosa dan Tuhan.

Kaum humanis cenderung memiliki gaya hidup bohemian dengan ditandai hampir selalu ada di kultur intelektual orang-orang barat, orang Eropa sampai hari ini. Seorang intelektual, filsuf, seniman dari dulu sampai sekarang bergaya hidup bohemian. Beberapa tokohnya humanisme awal: Desiderius Erasmus 27 Oktober 1466-12 Juli 1536 -70 tahun (belanda) adalah tokoh humanis awal. Di Itali ada Lorenzo (Laurentius) Valla 1407-1 agustus 1457 - 50 tahun. Memang tokohnya kebanyakan dari Itali yang sangat jeli mengawali pendangan kritis data-data sejarah. Giovanni Pico della Mirandola 24 Februari 1463 - 17 November 1494 - 31 tahun dan Giambattista Vico 23 Juni 1668 - 23 Januari 1744 - 74 tahun dan dari Inggris Sir Thomas More 7 Februari 1478 - 6 Juli 1535 - 57 tahun. Ada semangat awal sedikit berontak atas berpikir sendiri dari sisi manusiawi. Dikemudian hari ada juga William Shakespeare 26 April 1564 - 23 April 1616 - 52 tahun, Francois-Marie Arouet - Voltaire 21 November 1694 - 30 Mei 1778 - 84 tahun. Di spanyol ada Miquel de Cervantes Saavedra 29 September 1547 - 22 April 1616 - 69 tahun. Ini menandakan semangatnya melanda hampir di seluruh Negara Eropa, semangat protes-protes, semangat penemuan diri.

Selanjutnya sebetulnya hampir seluruh aktivitas modern, pemikiran modern berkarakter humanistik dalam arti merupakan refleksi terus menerus atas apa artinya menjadi manusia. Hampir segala filsafat dengan nama berbeda-beda itu sebetulnya adalah bentuk bentuk humanisme lanjutan. Dari Yunani klasik ada sistem pendidikan paideia, awal yang digunakan, sistem pendidikan yang mengutamakan kesehatan pikiran dan kebugaran tubuh.

\section{Humanisame Yunani Klasik dan Abad Pertengahan}

Pada masa Yunani klasik, humanism mengalami pembaharuan dari padangan manusia semata kodrati tentang manusia kepandangan manusia tidak sekadar makhluk kodrati tetapi juga makhluk adikodrati, imanen. Hal terjadi pada abad pertengahan perspektif Yunani klasik dimana manusia dipandang tidak hanya sebagai faber mundi (pekerja atau pencipta dunianya sendiri) tapi lebih pada imago dei; the image of God (makhluk ilahi atau citra Tuhan).

Humanismus; diciptakan oleh ahli pendidikan Jerman, F.J. Neithammer (1908) untuk menunjukkan tekanan pengajaran yang diberikan pada karya-karya klasik berbangsa Latin dan Yunani di sekolah-sekolah menengah. Berbeda dengan tuntutan dunia pendidian pada masa itu yang pengajarannya lebih berorientasi pada ilmu pengetahuan dan sains dan bersifat praktis. Tujuan pendidikan artes liberals adalah membebaskan peserta didik dari kebodohan dan kepicikan melalui pengembangan intelektual sehingga peserta didik menjadi manusia yang rasional, kritis, berwawasan luas, mampu bergaul secara manusiawi, cerdas, arif dalam membuat keputusan yang adil. Dengan kata lain, peserta didik menemukan bentuk kemanusiaannya yang benar, kodrat manusia yang real dan asli.

Menurut pandangan Yunani klasik, manusia ideal adalah manusia yang mengalami keselarasan jiwa dan badan, suatu kondisi dimana manusia mencapai eudaimonia (kebahagiaan). Keyakinan etis Sokrates, Plato, dan Aristoteles tentang tujuan hidup manusia eudaimonia, "well-being" atau hidup 
yang baik bertaut erat dengan pencitraan atas manusia ideal. Hal ini terjadi karena adanya pencitraan yang kodrati dan melulu menurut aturan akal budi atas manusia. Pada masa Isokrates (yang mewakili kaum Sofis) dan Plato, terdapat tujuh bidang pelajaran pada kurikulum tradisional Yunani klasik (artesliberales) yang merupakan konsepsi baru komprehensif tentang kultur ideal Yunani klasik.

Erasmus pada bukunya Praise of Folly (1511) menggambarkan tokoh Folly seorang perempuan, putri dewa Plutus muda yang agresif Youth yang cantik dan ceria. Erasmus melalui Folly mengidealkan kondisi alamiah dan manusiawi manusia. Folly mengatakan kebahagiaan dan keselamatan manusia tidak berasal dari luar, pengaruh adikodrati dan doktrin atau dogma tentang keselamatan. Pada kacamata pendidikan, Erasmus kebodohan dan kelemahan manusiawi lainnya secara inhern alami dalam diri setiap orang. Pendidikan sebagai wadah manusia menuju eksistensi dirinya, tidak hanya melatih seseorang mengetahui dan memahami prinsip-prinsip abstrak mengenai kebenaran dan moralitas. Aspek pengembangan fisik dan psikis atau afeksi dan psiko-motorik adalah dua aspek penting yang perlu berkembang agar kelebihan-kelebihan manusia menjadi akselerasi perkembangan seseorang.

Berbeda dengan Erasmus, Thomas More (1477-1535) membuat karya sastra yang berjudul Utopia dan bernuansa filsafat social. Karyanya ini berisi kritik terhadap situasi sosial dan politik pada abad ke 16 di Inggris. Berbeda dengan Erasmus menggunakan Folly sebagai tokohnya, Thomas More adalah seorang pengacara London menggunakan Utopia nama pulau yang didiami oleh masyarakat. Thomas More termasuk cendekiawan yang mengkritik sistem monarki dan sistem kapitalisme karena justru keduanya tidak membuahkan kesetaraan dan keadilan dalam negara. Masyarakat Utopia yang digambarkan oleh Thomas More adalah masyarakat yang memiliki identitas sistem dan struktur kehidupan bersama. Prinsip hidup masyarakat pada pulau Utopia adalah kegembiraan (pleasure), karena mereka percaya bahwa manusia memang "ditakdirkan" oleh alam untuk gembira. Kegembiraan yang sejati dicapai manusia dengan bantuan rasionya.

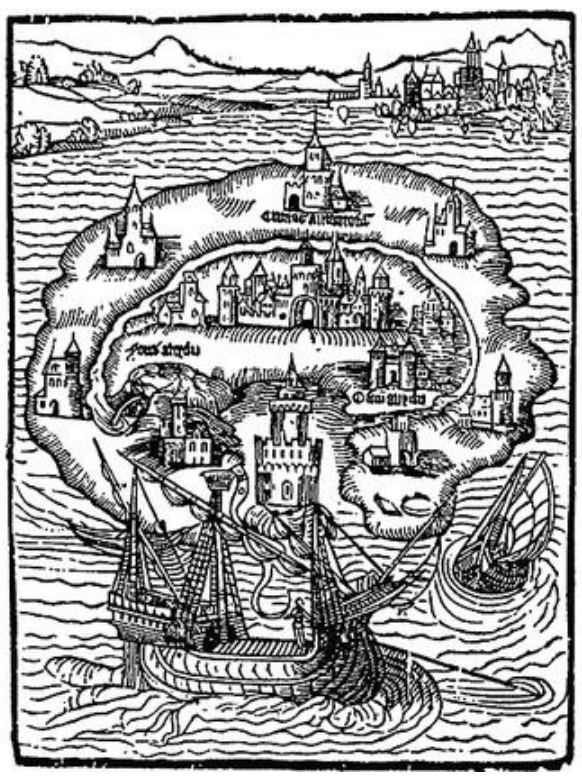

Gambar 1. Pulau Utopia pada Buku Thomas More

Sumber: https://techcrunch.com/2012/10/01/nyu-professor-open-sources-utopia-by-sir-thomas-more/

Masa Renaisans dapat dikatakan sebagai pembuka jalan pengembangan peradaban Eropa yang nantinya menyebar ke seluruh dunia. Pengaruhnya pada pendidikan, eksplorasi alamiah manusia, dan anti-kebakuan dan anti-kebekuan. 
- Pendidikan idealitas kemanusiaan terlihat dari penggunaan kurikulum artes liberales, trivium dan quadrivium. Aspek fisik, afeksi juga diolah dan dikelola dalam kurikulum pendidikan.

- $\quad$ Metode yang digunakan dalam pengajaran menggunakan empiris, pengalaman berupa observasi mengumpulkan data-data dan fakta. Menggunakan metode induktif dan mengganti metoe deduktif.

- $\quad$ Tidak adanya pembakuan di berbagai macam sendi kehidupan, sehingga tidak menghasilkan pembekuan paradigma dalam bentuk doktrin atau dogma sosial, politik, budaya, ekonomi, dan agama.

- $\quad$ Sekularisme adalah suatu gerakan yang dalam mengurus dan mengelola kehidupan ini tidak mau mengkaitkannya dengan urusan urusan religius, adikodrati, dan keakhiratan, melainkan mengarahkan diri pada konteks duniawi.

- Sekular (saeculum-bahasa Latin) yang memiliki arti ganda yaitu abad dan dunia. Sehingga arti dari sekularisme adalah cara pandang yang mrmbatasi diri pada yang temporal dan duniawi saja.

- $\quad$ Sekularisme berkembang pesat pada masa Romantik, meskipun sudah mulai tumbuh pada masa Renaisans. Pada masa gerakan ini, manusia semakin menyadari kedasyatan budayanya sendiri dan merasa tidak lagi tergantung pada konsep tentang transendensi. George J Holyoake (1846) mengemukakan sekularisme sebagai satu system etika dan filsafat secara formal.

- Dalam kehidupan sehari hari, kata sekular diartikan sebagai jauh dari hidup keagamaan, bukan wilayah rohani dan suci, melainkan urusan keduniawian, kebendaan.

Ini tiga ciri utama dunia modern. Pada abad 19 eksplorasi dan penekanan pada kemampuan manusia dalam konteks sekularnya menjadi semakin kuat dan tak terhindarkan.

\section{Homodeus}

Gerakan reformasi yang melahirkan nasionalisme, kapitalisme, dan demokrasi, sedangkan humanisme sekular sebagai cikal bakal gerakan reformasi tersebut. Filsafat bergerak dari sifat theosentris menjadi antroposentris dengan memiliki nilai dan sejarah pada setiap tahap perubahannya. Setiap perubahan gerakan dari masa ke masa memiliki besar sekali pengorbanan. Antroposentris menjadi pemahaman mendasar manusia saat ini. Keberhasilan mengatasi bencana yang demikian dahsyat dengan menggunakan teknologi, akal dan pikiran manusia membuat manusia semakin ingin memiliki kemampuan lebih tinggi dan lebih jauh.

Pada abad ke 20, manusia di dunia ini dilanda kelaparan, wabah, dan perang. Setiap generasi selalu berdoa kepada tuhan, malaikat. Santa untuk mengatasi bencana ini. Banyak pemikir menyimpulkan bencana ini adalah bagian integral dari rencana kosmis Tuhan. Pada saat kondisi terpuruk, beberapa orang mengatasinya dengan berdoa dan percaya bahwa kondisi ini merupakan salah satu rencana kosmis Tuhan. Pada saat bencana ini dapat diatasi, manusia merasakan itu adalah suatu kesuksesan yang menumbuhkan ambisi dan prestasi-prestasi muktahir. Dalam pikirannya, manusia menyikapi reaksi prestasi, bukan kepuasan, tapi mengejar lebih banyak. Pemikiran Nicolo Machiavelli, dimana manusia memang tetap makhluk yang brutal terlihat pada masa sekarang.

Pada abad 21, manusia akan melakukan upaya serius menuju imortalitas. Perjuangan melawan usia tua dan kematian hanyalah kelanjutan dari perjuangan yang paling dibanggakan sepanjang jaman melawan kelaparan dan penyakit, dan memanifestasikan nilai tertinggi budaya kontemporer: nilai kehidupan manusia. Adanya Deklarasi Universal Hak-hak Asasi Manusia, dimana dinyatakan setiap manusia punya hak untuk hidup. Hak hidup tersebut sama sekali tidak dibatasi oleh tanggal kedaluwarsa, untuk itu beberapa ilmuwan dan pemikir menyatakan misi andalan sain modern adalah mengalahkan kematian dan member manusia usia muda abadi. 
Hal ini sangat mungkin terjadi, karena manusia merasa sudah berhasil mereduksi angka kematian dari kelaparan, penyakit, dan kekerasan. Bahkan saat ini ada target untuk mengatasi usia tua dan kematian, setelah menyelamatkan orang dari penderitaan yang hina dina, kini target manusia adalah menuju kebahagiaan yang positif. Masih dalam konteks kebahagiaan, Desiderius Erasmus pernah menuliskan dalam bukunya Praise of Folly (1511), dimana dengan tokoh Folly: Kebahagiaan tersebut berasal dari dalam diri manusia, kebutuhan dan harapan moral bahwa manusia memiliki kemampuan internal untuk berkembang menjadi baik. Kebahagiaan mampu bertahan karena ditopang oleh dua pilar kokoh, yaitu psikologis dan biologis. Pada level psikologis, kebahagiaan bergantung pada ekspektasi, bukan kondisi-kondisi obyektif. Kebahagiaan hadir ketika realitas sesuai dengan ekspektasi kita. Berita buruknya adalah saat kondisi membaik, ekspektasi pun melambung. Pada level biologis, baik ekspektasi maupun kebahagiaan ditentukan oleh biokimia bukan oleh situasi ekonomi, social, atau politik.

Dalam mencari kebahagiaan dan imortalitas, manusia benar-benar berusaha untuk meningkatkan diri menjadi tuhan-tuhan-keilahian. Bukan hanya karena alasan kualitas ilahiah, tetapi juga karena alasan agar bisa mengatasi usia tua. Manusia memiliki keinginan untuk meningkatkan manusia menjadi tuhan mungkin akan menempuh jalan: rekayasa biologis, rekayasa cyborg, rekayasa benda-benda non-organik (Harari, 2015).

Warisan masa lalu, warisan reformasi sebagai pemicu lahirnya nasionalisme, kapitalisme, dan demokrasi menjadi pendorong untuk mengejar imortalitas, kebahagiaan, dan keilahian. Memprediksi bahwa manusia akan berusaha meraih mortalitas, kebahagiaan, dan keilahian adalah sama halnya dengan meramalkan. Dirasakan dan dipikirkan bahwa hal tersebut masuk akal. Selama 300 tahun dunia telah didominasi oleh humanisme, yang mengorbankan kehidupan, kebahagiaan, dan kekuatan Homo sapiens.

Pada 2016, dunia didominasi oleh paket liberal individualisme, hak-hak asasi manusia, demokrasi, dan pasar bebas. Sains meruntuhkan fondasi tatanan liberal, karena sains tidak mengurusi masalah nilai, tidak bisa menentukan apakah kaum liberal benar dalam menilai kebebasan lebih tinggi dari kesetaraan, atau dalam menilai individu lebih tinggi dari kolektif. Kaum liberal menilai kebebasan individu begitu tinggi karena mereka percaya bahwa manusia memiliki kehendak bebas.

Sains juga memberikan pengaruh pada melemahnya keyakinan liberal pada kehendak bebas dan keyakinan individualisme. Sejak meletupnya Revolusi Industri, orang takut bahwa mekanisasi bisa menyebabkan pengangguran massal. Manusia memiliki dua jenis kemampuan dasar: fisik dan kognitif. Sepanjang manusia bersaing dengan mesin dalam kemampuan fisik, tak terhitung pekerjaan kognitif yang yang bisa dilakukan oleh manusia dengan lebih baik. Namun apa yang terjadi jika algoritma menggungguli manusia dalam mengingat, menganalisis, dan mengenali pola pola?

1. Organisme adalah algoritma

2. Kalkulasi algoritmik tidak dipengaruhi oleh materi-materi dari kalkulator itu dibangun.

3. Algoritma organik bisa melakukan hal hal yang algoritma non-organik tidak pernah mampu replikasi atau lampaui,

Identifikasi beberapa ancaman praktis bagi liberalism, yaitu a. manusia mungkin menjadi tidak berguna secara militer dan ekonomi, b. dibutuhkan manusia yang bukan individu-individu dengan menghilangkan otoritas dan kemerdekaan individu-individu. Sains-sains kehidupan menantang ketiga asumsi tentang keyakinan liberal pada individualism, yaitu:

1. Organisme adalah algoritma dan manusia bukanlah individual-mereka adalah "dividual”. Manusia merupakan susunan dari banyak algoritma berbeda yang tidak punya suara batin tunggal atau diri tunggal. 
2. Algoritma membuat manusia tidak bebas.

3. Sebuah algoritma eksternal secara teoritis bisa tahu lebih baik tentang saya ketimbang yang pernah bisa saya ketahui tentang diri saya sendiri.

Perkembangan jaman, akan muncul agama baru yang akan muncul dari laboratoriumlaboratorium riset, yang disebut agama tekno. Agama tekno dibagi menjadi dua jenis utama yaitu tekno humanisme dan agama data. Tekno humanisme masih melihat manusia sebagai pusat penciptaan dan setuju bahwa Homo sapiens telah usai menjalani lintasan sejarahnya dan tidak akan relevan lagi pada masa depan. Selanjutnya akan menggunakan teknologi dalam rangka menciptakan homo dues-model manusia yang jauh lebih unggul.

Saat ini semua bersandar pada data, sehingga muncul Dataisme. Pengalaman manusia tidak sakral dan homo sapiens bukan pusat penciptaan atau pendahulu dari Homo dues masa depan. Lebih mengkhawatirkan lagi, manusia hanyalah alat-alat untuk menciptakan Internet-Segala-Hal yang mungkin akhirnya menyebar dari planet Bumi untuk merambah seantero galaksi dan bahkan segenap alam semesta. Manusia sebagai homo sapiens dikatakan oleh Yuval Noah Harari sebagai algoritma yang sudah usang. Lebih jauh dikatakan pula terdapat tiga proses yang saling terkait yaitu:

1. Sains sedang memusatkan diri pada satu dogma yang mencakup keseluruhan, yang menyatakan bahwa organisme adalah algoritma dan kehidupan adalah pemrosesan data.

2. Kecerdasan sedang berpisah dari kesadaran.

3. Algoritma non-kesadaran tetapi sangat pintar mungkin segera mengenal kita lebih baik dari kita sendiri.

\section{KESEIMBANGAN TERHADAP RESPON GAYA LUAR}

Kekhawatiran adanya Dataisme yang mengkerdilkan peran manusia dalam alam semesta ini sebenarnya tidak berdasar. Alam semesta ini akan memberi respon terhadap segala hal yang dilakukan manusia yang bersifat kreativitas, sehingga sebenarnya tidak ada kemungkinan kekhawatiran terhadap agama data atau dataisme. Begitu pula kejadian yang baru baru ini terjadi, gempa. Akibat gempa, manusia dengan segala kreativitasnya akan menjawab akibat gempa tersebut. Tidak hanya sekedar mencari jawaban untuk berlari menyelamatkan diri, tetapi pada bicara resiliensi. Konsep resiliensi bukan berada pada ranah imortalitas untuk mencapai kebahagiaan menuju keilahian, tetapi resiliensi berupaya untuk lebih banyak jatuhnya korban jiwa akibat teknologi yang kurang sempurna. Jika bangunan gedung dibangun menggunakan teknik yang benar dan perhitungan yang tepat, maka akan mengurangi jumlah korban jiwa akibat tertimpa bangunan pada saat gempa, ini berbeda dengan konsep imortalitas-kebahagiaan-keilahian.

Perbedaan terletak pada tujuan imortalitas, dimana pada konsep resiliensi, mempertahankan hidup pada saat terjadi gempa. Bukan mencari jalan untuk tetap hidup pada saat kondisi makmur, sehat wal afiat, segar bugar. Hal ini harus dipahami. Tentu rasa bahagia tersebut mengekor pada kemampuan hidup pada saat gempa terjadi, tetapi hulu rasa kebahagiaan tersebut berbeda dengan kebahagiaan merupakan hasil dari kemampuan menghasilkan "immortal" pada saat keadaan sangat baik. Sedangkan sifat keilahian tidak mengekor pada imortalitas dan kebahagiaan. Tidak ada rasa atau pemahaman keilahian tetapi lebih pada memperbaiki tataran dalam menjawab tantangan alam dengan lebih lembut dan santun. Langkah menjawab tantangan ini lebih pada mengikuti "kinerja" alam sebagai responnya. 


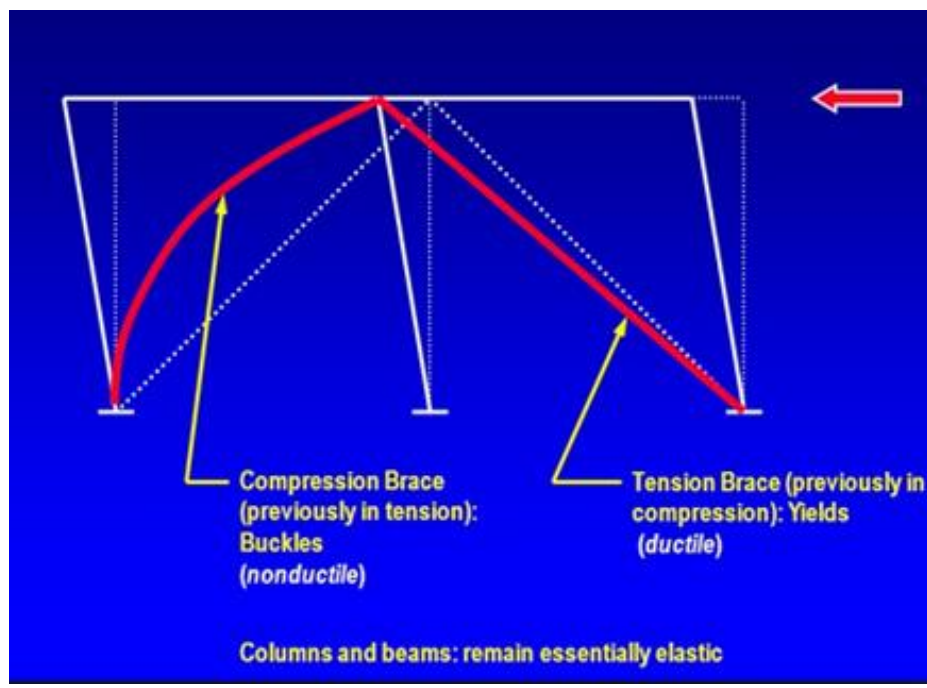

Gambar 2. Respon Gaya Luar Datang

Sumber: http://angryits.blogspot.com/2010/10/sistem-struktur-rangka-baja.html

Data-data gempa dan grafik untuk perhitungan resiliensi dipelajari dan diteliti dengan cermat untuk merespon kinerja alam semesta, bukan untuk "menantang" alam semesta dengan sifat tantangan imortalitas dam keilahian untuk mendapatkan kebahagiaan. Didalam ilmu struktur, gaya luar yang bekerja pada bangunan harus mempu direspon oleh system struktur bangunan gedung agar bangunan gedung tetap stabil, kokoh, dan kuat. Dikenal dengan istilah aksi-reaksi, lebih pada membuat system struktur tersebut seimbang, balance. Ketidakmampuan sistem struktur tersebut memberikan reaksi yang tepat baik arah maupun besar gaya, akan membuat bangunan gedung tersebut ambruk, rubuh. Reaksi yang diberikan oleh sistem struktur tersebut juga bukan reaksi yang berlebihan, tetapi reaksi yang sesuai dengan aksi yang datang akibat gaya luar. Reaksi yang berlebihan justru akan membuat sistem struktur bangunan gedung tersebut akan patah. Ini terlihat dari rumah tinggal tradisional yang menggunakan material kayu dengan pasak kayu sebagai konektor antarelemen struktur. Pada saat gempa, sistem struktur rumah tinggal nusantara ini akan bergerak bersama dengan gerakan yang diakibatkan oleh gempa. Sejauh gerakan gempa tidak mengakibatkan pasak terlepas, bangunan gedung akan tetap berdiri. Berbeda jika bangunan gedung menggunakan sambungan yang kaku untuk menghubungkan antarelemen bangunannya, seperti hubungan atau konektor antara kolom dan balok beton. Hubungan yang kaku/jepit membuat kedua elemen struktur tersebut tidak dapat bergerak atau merespon gerakan gempa, akibatnya patah antara kolom dan balok betaonnya. Ini bentuk ikatan yang benar-benar kuat dan kaku, sehingga jika salah satu elemen struktur diberi beban luar yang lebih besar (seperti beban gempa) maka elemen yang lain seharunya bisa membantu dengan memberikan respon gaya sehingga gaya yang datang.

\section{SIMPULAN}

Model resiliensi pada bangunan vital sehingga tahan terhadap gempa, bagian dari siklus dari alam semesta. Tidak ada "sosok" sains yang arogan, merasa kuat dan mampu berjalan tanpa bantuan manusia, tetapi hadirlah sains yang dapat menerima alam semesta sebagai partner dalam bekerja. Hal ini dapat terjadi karena manusia masuk di dalam atau bagian dari alam semesta. Dataisme atau agama data tidak dapat bekerja secara otomatis dan tepat. Unsur human pada penelitian ini tetap diperlukan. Penelitian bekerja tidak berupa angka-angka nominal, tetapi lebih pada pendekatan humanistik. 
86 Keseimbangan antara Aksi-Reaksi Gaya Luar Bangunan sebagai Keramahan terhadap Alam Semesta: Diskursus

\section{DAFTAR PUSTAKA}

Sugiarto, Bambang, Humanisme dan Humaniora Relevansinya Bagi Pendidikan, Pustaka Matahari, Bandung, 2008

Sugiarto, Bambang, Postmoderenisme Tantangan Bagi Filsafat, PT Kanisius, Yogyakarta, 2018

Nasution, M Syukri Albani, Filsafat Ilmu, Rajawali Pers, Depok, 2017

Harari, Yuval Noah, Homo dues, Alfabet, Tangerang Selatan, 2015 